\title{
Is Symptomatic Atherosclerotic Cerebrovascular Disease a Risk Factor for Normal-Tension Glaucoma?
}

\author{
İnci Ulu Güngör ${ }^{a}$ Levent Güngör ${ }^{b}$ Yakup Özarslan ${ }^{a}$ Nurşen Arıtürk ${ }^{a}$ \\ Ümit Beden $^{\mathrm{a}}$ Dilek Erkan ${ }^{\mathrm{a}}$ Musa Kazım Onar ${ }^{\mathrm{b}}$ ìhsan Öge ${ }^{\mathrm{a}}$ \\ Departments of a Ophthalmology and ${ }^{b}$ Neurology, School of Medicine, Ondokuz Mayıs University, Samsun, Turkey
}

\section{Key Words}

Normal-tension glaucoma $\cdot$ Glaucomatous optic neuropathy $\cdot$ Cerebral atherosclerosis $\cdot$ Cerebrovascular diseases

\begin{abstract}
Objective: To compare the incidence of glaucomatous optic disk appearance between patients with symptomatic atherosclerotic stroke and healthy individuals with normal intraocular pressures (IOP). Subjects and Methods: 46 patients with ischemic stroke with evident lacunar infarction or large vessel atherosclerosis, and 93 age- and sex-matched healthy individuals, all with normal IOP, were included. Patients and controls were examined for the presence of high cup-to-disk ratios (>0.5). Results: Seven patients (15.22\%) in the ischemic cerebrovascular disease (CVD) group and 3 controls (3.23\%) had glaucomatous optic disk appearance. All subjects with glaucomatous optic disk appearance in the control group and 3 patients in the study group had visual field defects in concordance with normal-tension glaucoma (NTG). The incidence of glaucomatous optic disk appearance was significantly higher in the group with symptomatic atherosclerotic CVD. Conclusion: Atherosclerotic CVD is a risk factor for having glaucomatous optic disk appearance. Symptomatic ath-
\end{abstract}

erosclerosis involving the brain vasculature may also affect the eye and lead to NTG. Patients with ischemic strokes due to large artery atherosclerosis or small artery occlusion must be examined and followed for NTG.

Copyright $\odot 2011$ S. Karger AG, Basel

\section{Introduction}

Normal-tension glaucoma (NTG) is typical glaucomatous optic nerve head damage and visual field changes with a normal intraocular pressure (IOP) $[1,2]$. NTG is a multifactorial disease, with vascular risk factors playing an important role in its etiology [3]. Certain vasospastic factors including migraine [4], Raynaud's syndrome, reduced finger blood flow [5] as well as blood flow disturbances such as hemodynamic crisis, low systemic blood pressure, nocturnal dips in blood pressure [6], hypertension $[6,7]$ and changes in the ciliary circulation have been associated with NTG $[2,3,6,8]$.

Half the patients in the collaborative NTG study have a history of cardiovascular disease [3]. It is also possible that cerebrovascular diseases (CVD) are associated with NTG [9]. CVD are more frequent in patients with NTG than in those with high-tension glaucoma or in normal

\section{KARGER}

Fax +4161306 1234

E-Mail karger@karger.ch

www.karger.com
(C) 2011 S. Karger AG, Basel

1011-7571/11/0203-0220\$38.00/0

Accessible online at:

www.karger.com/mpp
İnci Ulu Güngör, MD

Department of Ophthalmology

Ondokuz Mayıs University School of Medicine

TR-55139 Samsun (Turkey)

Tel. +90 3623121919 ext. 2627, Fax +90 362457 6041, E-Mail ligungor@ omu.edu.tr 
subjects [10]. Ischemic changes in brain magnetic resonance imaging (MRI) are more common in patients with NTG than in control subjects [2, 9], suggesting that vascular insufficiency in the central nervous system has some relation to the pathogenesis of NTG [11]. Systemic arteriosclerosis has been described as more prevalent in these patients [7] and may be a potential risk factor for glaucomatous optic nerve damage [12]. Nonetheless, the exact association between NTG and cerebral atherosclerosis is unclear.

In this study, in a group of subjects with low IOP, we tried to determine whether a relationship exists between glaucomatous optic disk changes and symptomatic atherosclerotic CVD, and we focused our attention on the possible role of ischemia in the pathogenesis of NTG with a short review of the literature.

\section{Subjects and Methods}

The study included 121 patients who had the diagnosis of ischemic CVD determined at the Department of Neurology, Ondokuz Mayıs University, Health and Research Hospital, between August 2005 and October 2007, and 93 healthy subjects with no ophthalmologic complaints and no known previous CVD. Only patients with normal IOP $(<22 \mathrm{~mm} \mathrm{Hg})$ [13] were included. Patients with a known history of primary open-angle and secondary glaucoma, pigmentary dispersion or exfoliation, gliotic optic nerve head changes associated with optic atrophy, significant retinal disease or media opacity preventing adequate posterior pole examination were excluded. Patients who initially received treatments lowering intracranial pressure - e.g. with mannitol, which may also lower IOP - were excluded.

A total of 121 stroke patients and 93 healthy subjects underwent ophthalmologic examination including anterior segment examination, fundoscopy, detailed optic nerve head investigation and IOP measurement. The presence of glaucomatous optic disk appearance was decided on by 2 ophthalmologists who were unaware of the patient's stroke subtype to minimize examiner-derived error. Patients who had a vertical or horizontal cup-to-disk $(\mathrm{C} / \mathrm{D})$ ratio of $>0.5$ in one eye together with glaucomatous papillary excavation, total cup, neural rim saucerization or neural rim notching in the inferior or superior-temporal disk areas were considered to have glaucomatous optic disk appearance. These patients were followed for $72 \mathrm{~h}$ for exclusion of IOP elevation, and computerized visual field testing was performed to demonstrate the presence of any visual field defect except in patients with acute stroke who were unable to cooperate with the test.

The diagnosis of CVD was confirmed by clinical evaluation and brain imaging findings. Ischemic stroke was defined as 'rapidly developing symptoms and/or signs of focal, and at times global loss of cerebral function, with symptoms resolving or leading to death with no apparent cause other than that of vascular origin with evidence of ischemia in brain computerized tomography (CT) or MRI' [14]. Five stroke subtypes were determined according to the Stop Stroke Study (SSS)-TOAST criteria $[15,16]$. Brain
CT or MRI, electrocardiography or 24-hour electrocardiography monitoring, transthoracic and transesophageal echocardiography with agitated saline if needed, carotid and vertebral artery duplex ultrasonography, brain and neck CT or MR angiography, and digital subtraction angiography of the head and neck when indicated were used for subtype identification. All patients had laboratory examinations including chest X-ray, complete blood count, thyroid function, routine blood biochemistry, coagulation tests, and serum erythrocyte sedimentation rate. Ischemic stroke subtype classification was done by a single stroke specialist experienced in this area and blinded to the ophthalmologic findings of the patients.

Among 121 patients with ischemic stroke, those with stroke related to evident cardioaortic embolism $(n=44 ; 36.36 \%)$ or other causes $(n=9 ; 7.43 \%)$, and those undetermined $(n=22 ; 18.28 \%)$ were excluded. Thirty patients with evident large artery atherosclerosis $(24.79 \%)$ and 16 with small artery occlusion (13.22\%) were included. Therefore, 46 patients with ischemic CVD due to atherosclerosis of cerebral vessels were included in the final analysis along with the 93 healthy controls.

We recorded age, gender, history of hypertension, diabetes mellitus, coronary artery disease (CAD) and smoking for patients and controls. All participants or relatives were informed about the study and each gave informed consent.

The presence of glaucomatous optic nerve head appearance (horizontal or vertical $\mathrm{C} / \mathrm{D}$ ratio of $\geq 0.5$ ) despite normal IOP $(<22 \mathrm{~mm} \mathrm{Hg}$ ), as well as age, gender, history of hypertension, diabetes mellitus, CAD and smoking data were compared between ischemic atherosclerotic CVD and control groups. Parameters like age, gender, atherosclerotic CVD, history of hypertension, diabetes mellitus, CAD and smoking were later examined as risk factors for the appearance of glaucomatous optic disk in this study population. The results were adjusted for each parameter by multivariate logistic regression analysis. The Fisher exact test, $\chi^{2}$ test and Mann-Whitney $U$ test were used for statistical analyses.

\section{Results}

The mean age in the atherosclerotic CVD group was $64.76 \pm 9.32$ years (range: $45-82$ years), and $62.99 \pm$ 12.24 years in the control group (range: $38-84$ years). The atherosclerotic CVD group included 18 women (39.13\%) and 28 men (60.87\%), and the control group comprised 43 women (46.24\%) and 50 men (53.76\%). The 2 groups did not differ significantly in age or gender (table 1).

Among the 46 patients with CVD due to small artery occlusion or large artery atherosclerosis and normal IOP, 7 (15.22\%) had glaucomatous optic disk appearance, and among the 93 control patients with normal IOP, 3 (3.23\%) had glaucomatous optic disk appearance. The rate of glaucomatous optic disk appearance and normal IOP was significantly higher in the atherosclerotic CVD group than in the healthy subjects $(\mathrm{p}<0.05$; odds ratio, $\mathrm{OR}=$ 5.385) (table 1). 
A history of hypertension and smoking were significantly more prevalent in the CVD group $(\mathrm{p}<0.01, \mathrm{OR}=$ 10.277 , for hypertension; $\mathrm{p}<0.05, \mathrm{OR}=3.048$, for smoking). A history of diabetes mellitus and CAD were also more common in the CVD group, but this was not statistically significant $(\mathrm{p}>0.05)$ (table 1$)$.

We analyzed if any of these parameters was a risk factor for having glaucomatous optic disk appearance. Age, gender, history of hypertension, diabetes mellitus, CAD, smoking and patient status as having symptomatic atherosclerotic CVD or not were placed in a multivariate

Table 1. Comparison of patients with high C/D ratio, HT, DM, $\mathrm{CAD}$ and smoking between atherosclerotic CVD and control groups

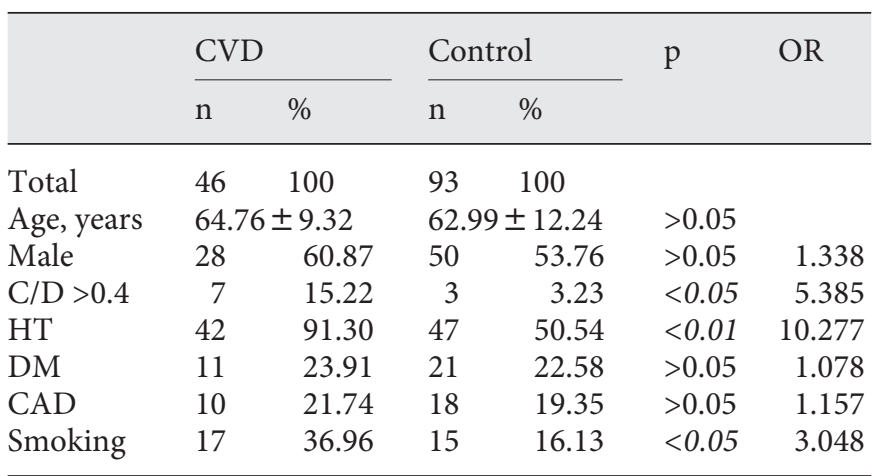

Figures for age are means \pm SD. Values in italics are statistically significant. $\mathrm{HT}=$ Hypertension; $\mathrm{DM}=$ diabetes mellitus; $\mathrm{OR}=$ odds ratio. model. Among these parameters, ischemic atherosclerotic CVD was the only significant risk factor for glaucomatous cupping of the disk in our study population $(\mathrm{p}<$ 0.05).

Glaucomatous optic disk appearance with a C/D ratio of $>0.5$ was present in 15 eyes among 19 eyes of 10 subjects. Fundoscopic examination could not be performed on 1 eye in the CVD group (patient No. 6) because of anterior segment opacity. The highest IOP measured during $72 \mathrm{~h}$ of follow-up ranged between 12 and $18 \mathrm{~mm} \mathrm{Hg}$ in the 19 eyes (mean: $14.1 \pm 1.89 \mathrm{~mm} \mathrm{Hg}$ ) with glaucomatous optic disk appearance. All of the subjects with glaucomatous optic disk appearance in the control group and 3 patients in the ischemic stroke group had typical visual field defects in concordance with glaucoma. Visual field defects were large central scotoma in 7 eyes and peripheral narrowing in 3 eyes of 6 patients. Four of the patients in the ischemic CVD group were unable to cooperate with visual field testing or were lost in long-term followup. Therefore, the definite diagnosis of NTG was not possible for these 4 patients in the CVD group. The clinical characteristics and ophthalmologic findings of the subjects with glaucomatous optic disk appearance are listed in table 2 .

\section{Discussion}

NTG involves a heterogeneous pathology of the optic nerve and retina [17]. The causes of NTG have not been definitively described, although a number of mecha-

Table 2. Ophthalmologic findings and vascular risk factors of the cases with a high C/D ratio

\begin{tabular}{|c|c|c|c|c|c|c|c|c|c|c|c|c|c|}
\hline \multirow[t]{2}{*}{$\begin{array}{l}\text { Patient } \\
\text { No. }\end{array}$} & \multirow[t]{2}{*}{ Group } & \multirow[t]{2}{*}{$\begin{array}{l}\text { Age } \\
\text { years }\end{array}$} & \multirow[t]{2}{*}{ Sex } & \multicolumn{2}{|c|}{$\mathrm{C} / \mathrm{D}$ ratio } & \multicolumn{2}{|c|}{$\begin{array}{l}\text { Ocular tension } \\
\mathrm{mm} \mathrm{Hg}\end{array}$} & \multicolumn{2}{|c|}{$\begin{array}{l}\text { Visual field } \\
\text { defect }\end{array}$} & \multicolumn{4}{|c|}{ Vascular risk factors } \\
\hline & & & & right & left & right & left & right & left & & & & \\
\hline 1 & CVD & 51 & $\mathrm{~F}$ & 0.5 & 0.5 & 16 & 15 & + & + & HT & - & - & - \\
\hline 2 & CVD & 53 & $\mathrm{M}$ & 0.5 & 0.6 & 17 & 16 & NA & NA & $\mathrm{HT}$ & $\mathrm{DM}$ & - & - \\
\hline 3 & CVD & 78 & M & 0.5 & 0.4 & 14 & 12 & NA & NA & $\mathrm{HT}$ & - & CAD & $\mathrm{Sm}$ \\
\hline 6 & CVD & 69 & $\mathrm{~F}$ & $?$ & 0.5 & 14 & 12 & NA & NA & $\mathrm{HT}$ & - & CAD & - \\
\hline 7 & CVD & 57 & $\mathrm{M}$ & 0.4 & 0.5 & 14 & 14 & + & + & $\mathrm{HT}$ & - & - & - \\
\hline 8 & Ctrl & 64 & M & 0.7 & 0.7 & 12 & 12 & + & + & - & - & CAD & - \\
\hline 9 & Ctrl & 55 & $\mathrm{~F}$ & 0.6 & 0.6 & 18 & 17 & - & + & $\mathrm{HT}$ & - & - & - \\
\hline 10 & Ctrl & 60 & $\mathrm{~F}$ & 0.6 & 0.6 & 15 & 15 & + & + & $\mathrm{HT}$ & $\mathrm{DM}$ & CAD & - \\
\hline
\end{tabular}

Ctrl = Control; F = female; $\mathrm{M}$ = male; $\mathrm{HT}$ = hypertension; $\mathrm{DM}=$ diabetes mellitus; $\mathrm{Sm}$ = smoking; $\mathrm{NA}=$ not available . 
nisms have been proposed, including vascular insufficiency, decreased optic disk resistance and effects of IOP [2]. Neurotoxicity and apoptosis triggered by ischemia may be the cause of progression $[8,12,18]$. Evidence has progressively accumulated suggesting that vascular insufficiency in the optic nerve head plays an important role in the pathogenesis of glaucomatous optic neuropathy $[1,2,7,12]$. Ischemia may be responsible for the cupping of the disk [19].

Patients with glaucoma suffer from inadequate ocular blood flow, which is independent of IOP $[8,12,20]$. The reduction in blood flow involves different parts of the eye, including the optic nerve head, choroid and retinal circulation, as well as retrobulbar blood flow [12]. Low ophthalmic artery pressure [7], local narrowing of the arteries at the optic nerve head border, reduced blood flow in conjunctival capillaries, local vasoconstriction in the retina [12], and lower peak systolic velocity and end diastolic velocity in central retinal arteries and short posterior ciliary arteries are described in patients with NTG [21].

Several cardiovascular and vasoocclusive diseases including cardiac arrhythmia, hemodynamic crisis, hypertension, hypotension [7], angina, silent myocardial ischemia [22], diabetes, peripheral vascular disease, CAD, atrial fibrillation, congestive heart failure, venous thrombosis [12], abnormalities of the coagulation and fibrinolytic system, dyslipidemia [7], hyperviscosity, vascular inflammatory diseases $[20,23]$ and migraine $[1,4]$ are reported to be more frequent in patients with NTG $[1,7$, $8,11]$. Besides these, several observations reveal no correlation between NTG and systemic noninvasive vascular profiles, coagulation tests and rheologic profiles, suggesting that the reason for decreased optic nerve perfusion must be localized or vasospastic [24].

Ischemic CVD may be the key point between the ocular blood flow disturbances, systemic vasooclusive diseases and NTG. Vascular insufficiency in the central nervous system has some relation to the pathogenesis of NTG $[9,11]$.

Patients with NTG may be suffering from diffuse ischemic damage throughout the brain [25]. In the report of Feldman et al., CVD were found to be more frequent in patients with NTG than in those with high-tension glaucoma or in normal subjects, but the subgroup of stroke was unclear in this study [10]. The NTG-specific features were related to an insufficient cerebral blood circulation caused by occlusive processes in the great and small vessels of the brain, especially those supplying blood to the upper corpus bigeminum, and of the optic nucleus of the lateral geniculate body [17]. Ong et al. [9] showed a great- er extent of cerebral infarcts in patients with NTG by using MRI. Confluent periventricular white matter lesions are found more often in patients with NTG than in control patients [2]. Some studies have shown histopathologic and sonographic evidence of reduction in blood flow of the globe in patients with stenosis or occlusion of the internal carotid artery. Internal carotid artery disease has been described to be more prevalent in patients with glaucoma $[7,26]$. Besides these, some investigators suggest that carotid stenosis, which may have an impact on ocular perfusion, is not or very weakly associated with glaucomatous optic nerve [12]. The exact correlation between cerebral and ocular hemodynamics is indefinite.

In this comparative cross-sectional study, we tried to answer the question whether cerebral symptomatic atherosclerosis is a risk factor for NTG. We examined only patients whose strokes were attributed to atherosclerosis of the cerebral vasculature (large vessel atherosclerosis and lacunar infarctions). Strokes related to causes other than cerebrovascular atherosclerosis, such as cardioaortic embolism, dissection or hypercoagulopathic disorders, and strokes with indefinite origin, were excluded. Our results reveal that patients suffering from acute stroke due to large artery atherosclerosis and small artery occlusion are at a higher risk of having glaucomatous cupping of the optic disk with normal IOP than are healthy individuals. The diagnosis of NTG depends on three aspects: classic optic disk changes, visual field defects and normal IOP. All of our patients with glaucomatous disk appearance had low IOP. However, we could demonstrate specific visual field defects in only 6 of 10 patients with glaucomatous optic disk appearance. We could not perform visual field tests and long-term followup necessary for ocular disease progression in approximately half of our stroke patients because of deteriorations in mental status or mortality. Therefore, it was impossible to make a full diagnosis of NTG in this category of patients. We did not exclude those patients with inappropriate clinical status from visual field tests and followup because of the risk of excluding patients with poor neurologic status and massive atherosclerosis in the cranial vasculature. However, these patients had glaucomatous optic disk appearance, low IOP and no previous history of ocular disease, and had, thus, a high probability of having NTG. Therefore, we believe that our results are meaningful for not only having glaucomatous optic disk appearance but also NTG. In addition, this was a hospital-based, observational study that was impossible to be designed in a completely blinded way. Another limitation is the finally low number of patients with glaucomatous 
optic disk appearance. One must be a bit daring to emphatically declare that symptomatic atherosclerotic CVD is a risk factor for NTG. However, the high prevalence of glaucomatous optic disk appearance in patients with symptomatic atherosclerotic strokes with normal IOP values observed in this study may support the hypothesis that NTG is a result of ocular blood flow disturbance. Atherosclerosis involving the brain vasculature may also affect the eye, leading to glaucomatous cupping of the optic disk.

We found no correlation between glaucomatous optic disk cupping and history of hypertension, CAD, diabetes mellitus and smoking in this study population, including those with ischemic stroke and healthy subjects with low IOP. The reason may be the low percentage of patients with glaucomatous optic disk appearance in our study group.

\section{Conclusion}

Symptomatic ischemic stroke due to small or large artery atherosclerosis is a risk factor for having glaucomatous cupping of the optic disk even if the ocular pressure is normal. Atherosclerosis of cerebral vessels may also affect ocular vessels and may lead to NTG. We believe that patients with ischemic stroke due to large vessel disease or lacunar infarction should be examined and followed for the presence of NTG.

\section{Acknowledgments}

The statistical methods for this study were developed and performed by Tevfik Sunter, MD, Department of Public Health, Ondokuz Mayis University, Turkey. The preliminary results without those of the control group were presented in poster session 40, National Congress of Ophthalmology, 2006, in Istanbul, Turkey.

\section{References}

1 Anderson DR, Drance SM, Schulzer M: Factors that predict the benefit of lowering intraocular pressure in normal tension glaucoma. Am J Ophthalmol 2003;136:820-829.

-2 Stroman GA, Stewart WC, Golnik KC, Cure J, Olinger RE: Magnetic resonance imaging in patients with low-tension glaucoma. Arch Ophthalmol 1995;113:168-172.

-3 Doyle A, Bensaid A, Lachkar Y: Central corneal thickness and vascular risk factors in normal tension glaucoma. Acta Ophthalmol Scand 2005;83:191-195.

4 Phelps CD, Corbett JJ: Migraine and lowtension glaucoma: a case-control study. Invest Ophthalmol Vis Sci 1985;26:1105-1108.

-5 Schulzer M, Drance SM, Carter CJ, Brooks DE, Douglas GR, Lau W: Biostatistical evidence for two distinct chronic open angle glaucoma populations. Br J Ophthalmol 1990;74;196-200.

6 Drance S, Anderson DR, Schulzer M: Risk factors for progression of visual field abnormalities in normal-tension glaucoma. Am J Ophthalmol 2001;131:699-708.

7 Hayreh SS: The role of age and cardiovascular disease in glaucomatous optic neuropathy. Surv Ophthalmol 1999;43(suppl 1):S27S42.

8 Landers J, Goldberg I, Graham SL: Analysis of risk factors that may be associated with progression from ocular hypertension to primary open angle glaucoma. Clin Exp Ophthalmol 2002;30:242-247.

${ }_{9}$ Ong K, Farinelli A, Billson F, Houang M, Stern M: Comparative study of brain magnetic resonance imaging findings in patients with low-tension glaucoma and control subjects. Ophthalmology 1995;102:1632-1638.
10 Feldman F, Sweeney V, Drance S: Cerebrovascular studies in chronic simple glaucoma. Can J Ophthalmol 1969;4:358-364.

-11 Suzuki J, Tomidokoro A, Araie M, Tomita G, Yamagami J, Okubo T, Masumoto T: Visual field damage in normal-tension glaucoma patients with or without ischemic changes in cerebral magnetic resonance imaging. Jpn J Ophthalmol 2004;48:340-344.

12 Flammer J, Orgül S, Costab VP, Orzalesi N, Krieglstein GK, Serra LM, Renard JP, Stefansson E: The impact of ocular blood flow in glaucoma. Prog Retin Eye Res 2002;21:359-393.

13 Schottenstein EM: Intraocular pressure and tonometry; in Ritch R, Shields MB, Krupin T (eds): The Glaucomas, ed 2. London, Mosby, 1996, vol 1, pp 407-428.

14 Hankey G, Jamrozik K, Broadhurst RJ, Forbes S, Burvill PW, Anderson CS, StewartWynne EG: Long-term risk of first recurrent stroke in the Perth Community Stroke Study. Stroke 1998;29:2491-2500.

15 Ay H, Furie KL, Singhal A, Smith WS, Sorensen AG, Koroshetz WJ: An evidencebased causative classification system for acute ischemic stroke. Ann Neurol 2005;58: 688-697.

16 Ay H, Benner T, Arsava EM, Furie KL, Shingal $A B$, Jensen $M B$, Ayata $C$, Towfighi $A$, Smith EE, Chong JY, Koroshetz WJ, Sorensen AG: A computerized algorithm for etiologic classification of ischemic stroke: the causative classification of stroke system. Stroke 2007;38:2979-2984.

17 Nesterov AP, Aliab'eva Z, Lavrent'ev AV: Normal-pressure glaucoma: a hypothesis of pathogenesis (in Russian). Vestn Oftalmol 2003;119:3-6.
18 Schwartz M, Yoles E: Self-destructive and self-protective processes in the damaged optic nerve: implications for glaucoma. Invest Ophthalmol Vis Sci 2000;41:349-351.

19 Nagata A, Mishima H, Choshi K, Shimada S, Furumoto Y: Fluorescein fundus angiography of optic nerve head in primary open angle glaucoma and low tension glaucoma (in Japanese). Nippon Ganka Gakkai Zasshi 1992;96:1423-1428.

20 Hamard P, Hamard H, Dufaux J, Quesnot S: Optic nerve head blood flow using a laser Doppler velocimeter and haemorheology in primary open angle glaucoma and normal pressure glaucoma. Br J Ophthalmol 1994; 78:449-453.

21 Rankin SJA: Color Doppler imaging of the retrobulbar circulation in glaucoma. Surv Ophthalmol 1999;43(suppl 1):S176-S182.

22 Kaiser HJ, Flammer J, Burckhardt D: Silent myocardial ischemia in glaucoma patients. Ophthalmologica 1993;207:6-7.

23 Zeyen T: Screening for vascular risk factors in glaucoma: the GVRF study. Bull Soc Belge Ophtalmol 2005;298:53-60.

- 24 Carter CJ, Brooks DE, Doyle DL, Drance SM: Investigation into a vascular etiology for low-tension glaucoma. Ophthalmology 1990;97:49-55.

25 Orgül S, Gugleta K, Flammer J: Physiology of perfusion as it relates to the optic nerve head. Surv Ophthalmol 1999;43(suppl 1):S17-S26.

26 Orzalesi N, Rossetti L, Omboni S: Vascular risk factors in glaucoma: the results of a national survey. Graefes Arch Clin Exp Ophthalmol 2007;245:795-802. 